$\angle$ Research Square
Preprints are preliminary reports that have not undergone peer review.

They should not be considered conclusive, used to inform clinical practice, or referenced by the media as validated information.

\title{
Combined Mode of Courses on Dental Virtual Clerkship During COVID-19 Pandemic for Final-year Undergraduates in Wuhan
}

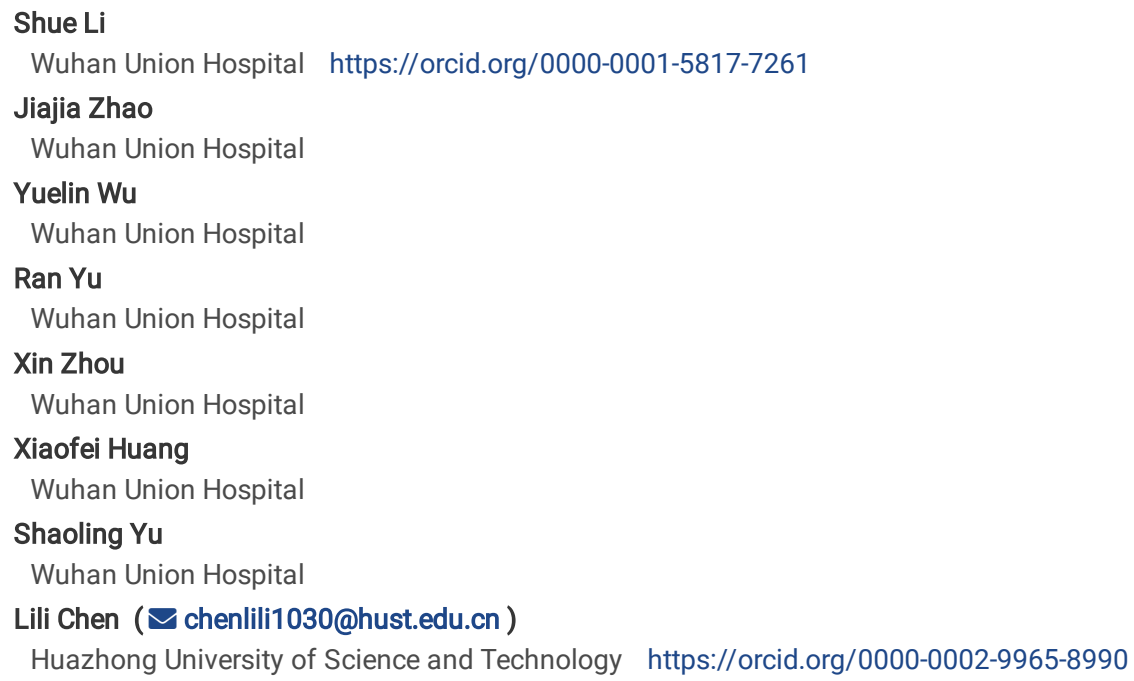




\section{Abstract}

Background

Online teaching is being widely adopted to achieve medical teaching objectives during the COVID-19 pandemic. To explore the dental virtual clerkship so as to continue the education of final-year dental undergraduate interns, combined mode of courses including small private online course, problem-based learning, online dental practice broadcasting and dental practice based on relatives' or friends' oral health management were applied for clerkship education for finalyear interns.

Methods

Combined courses of virtual clerkship was conducted from March to May, 2020 for final-year interns, while online preclerkship curriculum teaching was conducted for non-final-year students. Using the online students' engagement scale (OSE), Biggs' revised two-factor version of the study process questionnaire (R-SPQ-2F), student engagement and study process were evaluated for both. Teaching efficacy were evaluated via teachers' sense of efficacy scale (TSES) as well.

Results

Students' engagement was higher in final-year students, especially the emotion and participation categories $(\mathrm{P}<0.01)$. In the emotion category, $80.95 \%$ identified with putting forth effort on lecture and applying knowledge to life. Study approaches on deep motive and strategy were dominated in final-year interns $(P<0.01)$. Teacher' sense of efficacy also reflected the positive influence on student virtual clerkship. There was no significant difference among three categories including the sense of student engagement, instructional strategies and classroom management $(P>0.05)$.

Conclusion

This combined mode of courses on dental virtual clerkship could be potentially applied during the pandemic or be supplementary for traditional by-chair clerkship after the pandemic.

\section{Background}

The coronavirus disease 2019 (COVID-19) has great impact on both people's life and medical education [1, 2]. Final-year dental undergraduates from School of Stomatology, Tongji Medical College, Huazhong University of Science and Technology in Wuhan, China had finished the first semester clerkship and started winter vacation at the end of January. Later, all teaching activities in classroom of the second semester were cancelled and students will not return for the second semester of the 2019-2020 academic year. The transition was feasible for lectures and group discussion coursework, since large scales of online teaching is being adopted to achieve medical teaching objectives during the COVID-19 pandemic [3-5].

Traditional face-to-face learning experiences like dental clinical practice training for final-year dental undergraduate, however, are much more challenging to adapt to a virtual form [6, 7]. During severe acute respiratory syndrome (SARS) pandemic in 2003, the cessation of clinical clerkships, medical formal teaching on wards, exams and electives for students hindered the education of medical students $[8,9]$. Likewise, the cancellation of clerkships this time could be detriment for both skill acquisition and relationship building [1]. There is uncertainty on how long the pandemic will persist and more and more realize that there may be periods in the future even after this emergency events, in which social distancing or quarantines may still or again be required [3]. At this especial time, Online teaching and e-learning seems to be a proper way to continue clinical practice education for interns. Recent publications reported that, both written and video-based materials were synergistic in promoting ophthalmic knowledge acquisition and clinical skills for undergraduates [10]. The massive open online course micro-video mode was explored to enhancing nurse clinical skills as well during the pandemic [11]. Zooming-out virtual clinical experiences were also tried in an emergency medicine clerkship [12]. Virtual format would do help on clerkship education.

The aim of this study was to find advantages and disadvantages with combined online teaching approaches in Tongji Medical College for final-year dental interns. This combined mode could be a necessary temporary replacement for traditional by-chair clinical demonstration during pandemic or could be utilized in "normal" times later as well, promoting teaching efficacy and decreasing cost. Student engagement and study process were very important for preventing online learner dropout and evaluation of students approaches, which could reflect student learning status [13, 14]. Different questionnaires were applied for investigation of online learning student engagement and study process at this time, and comparison was made between final-year interns and non-final year students who were having online preclerkship curriculum at the same time, so as to evaluate the students' online learning efficacy. Teachers' sense of efficacy on virtual learning for dental students clinical training programs was also evaluated.

\section{Methods}

\section{General data}

All final-year dental undergraduate interns from a medical college, were enrolled in the study (18 females and 6 males, group 1 ) with the average age 23.46 \pm 0.93 . All the students from other grades who are still receiving preclerkship theory curriculum via virtual platform (Chaoxing platform, China) with online learning videos were taken as control group. There were 82 females and 39 males, with average age 21.6 \pm 1.48 .

Teaching method for final-year dental undergraduate interns 
During the COVID-19 outbreak, the final-year dental students would probably not be back for face-to-face dental practice clerkship. In order to continue by-chair clinical practice training and try to be close to clinical activities, a four-pronged approach was devised to provide an effective learning experience for final-year dental undergraduates.

1. Small private online course (SPOC). SPOC was developed via WeChat broadcasting platform (Tencent, China). Over 17 sessions including 7 sub-majors of dentistry were designed and each session was designed to have 1-2-hour classes with general and main operate technique required for students. Tutors were required to provide both theory and dental practice micro-videos. The PowerPoint and micro-videos were uploaded for review after class. 1-2 quizzes on operation were proposed every week and videos were required to be sent in 20 minutes after the quizzes started.

2. Problem-based learning (PBL). Both case reports and questions were released 2 days before the discussion. The students are split into small groups of around 8-10 students for a single 1-hour tutorial on WeChat group talk platform (Tencent, China). In the discussion, students were the main participators while tutor were required to guide the talk. The group went through each case, revised clinical skills and highlighted important points, clinical knowledge and pitfalls. Questions were raised anytime during the discussion. At the end of the block, assessment was conducted according to the performance and activity during the time.

3. Online dental practice broadcasting. Live broadcast was released on WeChat broadcasting platform (Tencent, China) including type $V$ restoration with glass ionomer and gingiva biopsy when the clinics were reopened in April in Wuhan. Informed consent was signed. Tutors were doing dental practice while commentating.

4. Dental practice based on relatives' or friends' oral health management. This cession was divided into two small parts. Students had to hand over general oral examination on anterior teeth for either themselves or their relatives who lived with them all the time during the pandemic. Those confirmed with COVID-19 disease, any indicators or symptoms related to the disease were strongly inhibited for oral examination. A general oral examination form was filled out. Oral health administration of dental students' relatives was also encouraged. Paper work on the consultation process of dental problem, final advice and discussion of the case needed to be finished. Final assessment was applied according to the paper work.

\section{Questionnaires}

Questionnaires on the students' engagement and study process and teachers' sense of efficacy were converted into online format by using the Questionnaire Star software (https://www.wjx.cn/). Information on gender, age and study year were also required in the questionnaires.

1. Online Students' Engagement scale (OSE). Students engagement were evaluated by means of OSE [15, 16]. The questionnaire has 19 Likert-type items with skills, emotions, participation, and performance categories. Each of them was scored on five-point Likert scale. Responses were 1=not at all characteristic of me, 2=not really characteristic of me, 3=moderately characteristic of me, 4=characteristic of me, and $5=\mathrm{very}$ characteristic of me. The Cronbach's alpha coefficients was $\mathrm{a}=0.94$.

2. Biggs' revised two-factor version of the Study Process Questionnaire (R-SPQ-2F). The questionnaire consists of 20 revised items on both deep and surface learning approaches. Achieving strategy and motive were included in the subscales. There were 10 items for each approach. The R-SPQ-2F is a reliable tool for measuring the learning approaches of students in university $[17,18]$. It has a 5 -point scale including $1=$ the responses were rarely true of me, $2=$ sometimes true of me, $3=$ half the time true of me, $4=$ frequently true of me, and $5=$ always true of me. Cronbach's a coefficients for deep learning was 0.86 and for surface learning is 0.77 .

3. Teachers' Sense of Efficacy Scale (TSES, long form). The TSES, developed by Tschannen-Moran and Hoy [19] is a valid instrument measuring teachers' sense of efficacy [20]. It is a nine-point Likert scale ( $1=$ nothing, $9=a$ great deal) with 24 items and three subscales. Subscale "student engagement" is a teacher's sense to make sure students are engaged in learning actively. Subscale "classroom management" means a teacher's ability to instruct the students achieving learning objectives positively, and "instructional strategies" suggests a teacher's ability in applying proper strategies for learning. Cronbach's a coefficient was 0.97 .

Data Analysis: SPSS 23 (Chicago, USA) was used for data analysis, which was expressed as $(M \pm S D)$. The counting data were described by numbers and percentage. To compare the mean scores of two different groups, independent t-test was performed. It was taken as statistically significant with P-value $<0.05$.

\section{Results}

\section{Study population}

Of a total number of 24 students at the final year, 21 (87.50\%) completed OSE and 20 (83.33\%) completed the R-SPQ-2F. For the TSES, 26 tutors were enrolled in the teaching activity and $23(88.46 \%)$ questionnaires were actually recovered. The non-final-year group was matched with final-year group for gender and age \pm 2 years for both questionnaires.

\section{Online Student engagement and outcomes (Table 2, Figure 1 A)}

The total mean score of final-year group was $71.33 \pm 13.11$, with the minimum and maximum scores 41 and 91 , respectively.

$76.19 \%$ students thought they were organized, listening/reading carefully and taking good notes. Item 5,6 and 7 has the highest mean 4.10 in this category. In the Emotion subscale, $80.95 \%$ identified with item 2 and 9 on putting forth effort and applying to life. In the participation category, $66.7 \%$ identified with item 12 and only $23.81 \%$ with item 19 . The means are 3.86 and 2.86 respectively, indicating that knowing each other was not the main purpose in class. However, the performance subscale in Item 15 and 16 are below $50 \%$ with the mean score 3.43 for item 15 and 3.48 for item 16 . Respondents are not so identified with getting good scores or do well on examinations. Whereas, compared with students in other grades, the total scores in emotion and participation categories are significantly higher than those in other grades $(P<0.01$, Figure $1 \mathrm{~A})$ 


\section{Biggs' Study Process and outcomes (Table 3, Figure 1B)}

The mean scores in both deep and superficial learning way are shown in Table 3. Compared with junior students, the scores in deep motive, strategy and approach is significantly higher in the final-year dental students (DA,DS: $P<0.001, D M: P<0.01$, Figure 1B).

\section{Teachers' Sense of Efficacy and outcomes (Table 4)}

The mean scores for subscales student engagement, instructional strategies and classroom management were $52.00 \pm 8.46,54.09 \pm 9.82$ and $53.43 \pm 9.01$ respectively $(P>0.05)$. For the efficacy in student engagement, the number of scores more than 5 which means identifying with the item was above $65.22 \%$, and item 12 has the highest percentage $91.30 \%$, which implied the ability to foster students' creativity during class. For the efficacy in instructional strategies, the percentage were all above $56.52 \%$. For item 7,10 and 11 , which suggested the ability of respondent to difficult questions raised by students, gauging their comprehension and crafting good questions, they had the highest percentage $91.30 \%$. However, for item 17 on ability of costuming teaching for individual students, there were only 13 people (56.52\%), who thought they could have some influence on adjusting their lessons to the proper level for individual students. For classroom management efficacy, item 13 on the ability to get students to follow rules during class had the highest percentage ( $91.30 \%$ ) and item 21 on the ability of respondent to defiant students had the lowest percentage (65.22\%).

\section{Discussion}

Despite reporting some issues with "virtual clerkship", which is challenging in providing real patients experiences for medical students [3], combined mode of course on dental virtual clerkship seems to provide enough efficacy for both teacher and students and to be a key substitute component under this circumstance. 80.95\% final-year students performed well on emotion category, suggested the strong desire to learn and apply the knowledge. Compared to non-final-year student who were also having online theory courses, score of the participation category was also higher which suggested the better engagement in this combined mode than that of non-final year online learners (Table 2, Figure 1A). Increase in DA in final-year students suggested the study process was performed well, meanwhile, the students were adapting to the online and student-centered learning gradually with the application of combined courses [21] (Table 3, Figure 1B). The self-efficacy of tutors was high and consistent with other research [22], indicating that tutors had good sense of the efficacy and the ability to direct the learning process of their student [23]. The majority of the respondents have a high efficacy in all three sub-dimensions of self-efficacy with no significant difference (Table 4).

The student engagement of online course is very important for the retention of online learners [24, 25]. With analysis of feedback on student engagement, it can be concluded that final-year students were interested in learning. Students thought they engaged in activities, focused on teaching materials, try their best, and deserved good scores [26]. The attitude towards grades on item 15 and 16 suggested that the expectation was higher than reality (Table 1). Some students reflected that there were many quizzes, which might be the reason for low score for item 15 and 16 . Teaching assessment should be re-assigned and designed for students.

Learning approaches were usually indicated of learners' perceiving, interaction with and responding to the learning environment [27]. Proper teaching methods are involved which could be applied allowing students to learn most effectively [26]. If students' learning approaches have been identified, proper teaching formats could be implemented and applied [28]. In this study, mean scores of deep approaches including learning motive and strategy were found higher among students in years 5 (Table3, $\mathrm{P}<0.01$ ). Our study is consistent with Newble and Gordon's study, which reported that high scores were found on DA in senior medical students [29]. The observed higher DA score in years 5 students might suggest a carry-over from post-graduate examination that is both externally and internally driven and education background might be a key factor for learning approaches [30]. Different format of teaching might be another explanation [31]. Lectures in other grades are mainly micro-video class for theory, which was uploaded onto the online platform. Whereas, in the years 5, various types of study and teaching mode were carried on so as to simulate clinical practice as much as possible and some of them were PBL, which was proved to increase in a deep learning [32,33]. In addition, workload or other factors, may be more as determinants than course type as well [21].

Though traditional by-chair clerkship is irreplaceable, the advantage for this combined virtual clerkship mode are as follows (Table 5). Taking SPOC, which could be repeatedly watched by the trainees, could greatly improves training effect [11]. The application of PBL and the exploration and practice of health management has been widely applied in Tongji Medical College [34], especially the dental health management and consultation from family or friend, making the role of dentist impressive. The clinic was reopened on April $8^{\text {th }}$, which make the live broadcasting available. Self-perceived student-to-tutor interaction was kept constant in both face-to-face and live broadcast [35]. Student Combined mode of SPOC, group talking, live broadcasting, health management for dental students' relatives is utilization of network tools to present clerkship courses, which could simulate to the maximum of by-chair clinical practice, providing patient medical histories, oral examinations, medical recording, and the art of detective conversations.

We learned several lessons as well. First, make sure all potential users could use the application. It's very challenging on the willingness of faculty to embrace the new technology [40]. Anything, including poor connection, or unfamiliar with apps operation should be taken into consideration first. With the reflection of such problems, teaching assistants helping both teachers and student to solve problems which often disrupt the flow of the class. Second, videos are encouraged to use for both teachers and students, which may improve the sense of interacting and engaging for both speakers and listeners. However, it's better to blur the participants' background for privacy protection, while unintended interruptions should also be avoided.

Difficulty in teaching dental practice via internet is still the main limitation. To learn these techniques, simulated patients are needed. Traditional by-chair learning is still a more effective way for medical education [7].

As social distancing is needed during pandemic, the combined virtual mode has significantly changed the way of teaching and engaging with our dental interns. Additionally, it has helped us to foster a sense of attenuating intern's burnout and to some extent promote dental wellness especially during or after the 
isolation. Combined modes of courses on virtual learning program may play a important role in medical clerkship education during or after the pandemic.

\section{Conclusion}

With combined mode of courses on dental virtual clerkship, the student engagement and study process of final-year students were more improved than those of non-final-year students. This mode could be potentially applied during the pandemic or be supplementary for traditional by-chair clerkship after the pandemic.

\section{Abbreviations}

COVID-19: the coronavirus disease 2019, SPOC: small private online course, PBL: problem-based learning, OSE: Online Students' Engagement scale, R-SPQ-2F: Biggs' revised two-factor version of the Study Process Questionnaire, TSES: Teachers' Sense of Efficacy Scale, DA: deep approach, DM: deep motive, DS: deep strategy, SA: superficial approach, SM: superficial motive, SS: superficial strategy.

\section{Declarations}

\section{Acknowledgements}

The authors would like to acknowledge Dr. Hui Ding, Jiarong Liu, Jun Han, Zheng Huang, Ting Chang, Yumei Ding, Zhenglin Yuan, Gaoxia Liu, Zhen Zhang, Jinhuan Geng, Lili Xu, Yang Liu, Zhenyu Shen, Mi Zhou, Yan Wu, Li Hu, Qian Liu, Fengyuan Guo, Liqun Zhou, Jiangyuan Song, Junyi Zhu, Xin Yu, Zhi Xu, Mingyu Sun, You Wu, et.al for their kind help.

\section{Authors' contributions}

S.L.: Contributed to design, data acquisition and interpretation, drafted and revised the manuscript. J.Z.: Contributed to statistical analysis and manuscript revision. Y.W., X.Z. and R.Y.: Contributed to teaching activity coordination and data acquisition. X.H. and S.Y.: Contributed to data analysis. L.C.: Contributed to design and critical revision of manuscript.

\section{Funding}

This study was supported by Provincial Teaching Research Project in Hubei Province (2017062) and Teaching Reform Research Project in Union Hospital, Tongji Medical College, Huazhong University of Science and Technology (2019025).

\section{Availability of data and materials}

Data are available from the corresponding author with reasonable request.

\section{Ethics approval and consent to participate}

The online courses study was conducted with prior approval from institutional ethics committee (IEC,20200406), which has waived the informed consent since it's a part of training program.

\section{Consent for publication}

Not applicable

\section{Competing interests}

No conflict of interests

\section{Author details}

1. Department of Stomatology, Union Hospital, Tongji Medical College, Huazhong University of Science and Technology, Wuhan 430022, China.

2. School of Stomatology, Tongji Medical College, Huazhong University of Science and Technology, Wuhan 430022, China.

3. Hubei Province Key Laboratory of Oral and Craniomaxillofacial Development and Regeneration, Wuhan 430022, China.

\section{References}

1. Ferrel, M.N. and J.J. Ryan. The Impact of COVID-19 on Medical Education. Cureus. 2020; 12(3): e7492; Available from: https://doi.org/10.7759/cureus.7492.

2. Ahmed, H., M. Allaf, and H. Elghazaly. COVID-19 and medical education. Lancet Infect Dis. 2020; 20(7): 777-778; Available from: https://www.ncbi.nlm.nih.gov/pubmed/32213335.

3. Wayne, D.B., M. Green, and E.G. Neilson. Medical education in the time of COVID-19. Science Advances. 2020: eabc7110; Available from: https://advances.sciencemag.org/content/advances/early/2020/06/04/sciadv.abc7110.full.pdf. 
4. Abi-Rafeh, J. and A.J. Azzi. Emerging role of online virtual teaching resources for medical student education in plastic surgery: COVID-19 pandemic and beyond. J Plast Reconstr Aesthet Surg. 2020; Available from: https://www.ncbi.nlm.nih.gov/pubmed/32553546.

5. Rose, S. Medical Student Education in the Time of COVID-19. JAMA. 2020; 323(21): 2131-2132; Available from: https://www.ncbi.nlm.nih.gov/pubmed/32232420.

6. Calhoun, K.E., L.A. Yale, M.E. Whipple, S.M. Allen, D.E. Wood, and R.P. Tatum. The impact of COVID-19 on medical student surgical education: Implementing extreme pandemic response measures in a widely distributed surgical clerkship experience. Am J Surg. 2020; 220(1): 44-47; Available from: http://www.ncbi.nlm.nih.gov/pubmed/32389331.

7. Shih, K.C., J.C. Chan, J.Y. Chen, and J.S. Lai. Ophthalmic clinical skills teaching in the time of COVID-19: A crisis and opportunity. Med Educ. 2020; 54(7): 663-664; Available from: https://www.ncbi.nlm.nih.gov/pubmed/32324929.

8. Clark, J. Fear of SARS thwarts medical education in Toronto. BMJ. 2003; 326(7393): 784; Available from: https://www.ncbi.nlm.nih.gov/pubmed/12689971.

9. Patil, N.G., Y. Chan, and H. Yan. SARS and its effect on medical education in Hong Kong. Med Educ. 2003; 37(12): 1127-8; Available from: https://www.ncbi.nlm.nih.gov/pubmed/14984121.

10. Hogg, H.D.J., M. Pereira, J. Purdy, R.J.R. Frearson, and G.B. Lau. A non-randomised trial of video and written educational adjuncts in undergraduate ophthalmology. BMC Med Educ. 2020; 20(1): 10; Available from: https://www.ncbi.nlm.nih.gov/pubmed/31918692.

11. Zhou, T., S.F. Huang, J. Cheng, and Y.R. Xiao. The Distance Teaching Practice of Combined Mode of Massive Open Online Course Micro-Video for Interns in Emergency Department During the COVID-19 Epidemic Period. Telemedicine and E-Health. 2020; 26(5): 584-588; Available from: https://doi.org/10.1089/tmj.2020.0079.

12. Chandra, S., C. Laoteppitaks, N. Mingioni, and D. Papanagnou. Zooming-out CoVID-19: Virtual clinical experiences in an emergency medicine clerkship. Med Educ. 2020; Available from: https://www.ncbi.nlm.nih.gov/pubmed/32502282.

13. Carini, R.M., G.D. Kuh, and S.P. Klein. Student Engagement and Student Learning: Testing the Linkages*. Research in Higher Education. 2006; 47(1): 1-32; Available from: https://doi.org/10.1007/s11162-005-8150-9.

14. Malik, A.A., R.A. Khan, H.N. Malik, A. Humayun, N.S. Butt, and M. Baig. Assessing reliability and validity of Revised Biggs Two-Factor study process questionnaire to measure learning approaches among undergraduate medical students in Lahore, Pakistan. J Pak Med Assoc. 2019; 69(3): 337-342; Available from: https://www.ncbi.nlm.nih.gov/pubmed/30890824.

15. Dixson, M.D. Creating Effective Student Engagement in Online Courses: What Do Students Find Engaging? Journal of the Scholarship of Teaching and Learning. 2010; 10(2): 1-13; Available from: https://files.eric.ed.gov/fulltext/EJ890707.pdf.

16. Dixson, M.D. Measuring Student Engagement in the Online Course: The Online Student Engagement Scale (OSE). Online Learning. 2015; 19(4): 143-158; Available from: http://dx.doi.org/10.24059/olj.v19i4.561.

17. Biggs, J., D. Kember, and D.Y. Leung. The revised two-factor Study Process Questionnaire: R-SPQ-2F. Br J Educ Psychol. 2001; 71(Pt 1): 133-49; Available from: https://doi.org/10.1348/000709901158433.

18. Shaik, S.A., A. Almarzuqi, R. Almogheer, O. Alharbi, A. Jalal, and M. Alorainy. Assessing Saudi medical students learning approach using the revised twofactor study process questionnaire. Int J Med Educ. 2017; 8: 292-296; Available from: https://doi.org/10.5116/ijme.5974.7a06.

19. Tschannen-Moran, M. and A.W. Hoy. Teacher efficacy: capturing an elusive construct. Teaching and Teacher Education. 2001; 17(7): 783-805; Available from: https://doi.org/10.1016/S0742-051X(01)00036-1.

20. Klassen, R.M., M.M. Bong, E.L. Usher, W.H. Chong, V.S. Huan, I.Y.F. Wong, et al. Exploring the validity of a teachers' self-efficacy scale in five countries. Contemporary Educational Psychology. 2009; 34(1): 67-76; Available from: https://doi.org/10.1016/j.cedpsych.2008.08.001.

21. Mirghani, H.M., M. Ezimokhai, S. Shaban, and H.J.M. van Berkel. Superficial and deep learning approaches among medical students in an interdisciplinary integrated curriculum. Education for health (Abingdon, England). 2014; 27(1): 10-14; Available from: https://doi.org/10.4103/1357-6283.134293.

22. ABD. Rahim Bakar, M.M.K., Rashid Jamian, Novel Lyndon. Teaching Efficacy of Universiti Putra Malaysia Science Student Teachers. College Student Journal. 2008; 16(1): 1-14; Available from:

http://www.pertanika.upm.edu.my/Pertanika\%20PAPERS/JSSH\%20Vol.\%2016\%20(1)\%20Mar.\%202008/04\%20Page\%201-14.pdf.

23. Cheung, H.Y. Teacher efficacy: A comparative study of Hong Kong and Shanghai primary in-service teachers. Australian Educational Researcher. 2008; 35(1): 103-123; Available from: https://doi.org/10.1007/BF03216877.

24. Banna, J., M.F. Grace Lin, M. Stewart, and M.K. Fialkowski. Interaction matters: Strategies to promote engaged learning in an online introductory nutrition course. J Online Learn Teach. 2015; 11(2): 249-261; Available from: https://www.ncbi.nlm.nih.gov/pubmed/27441032.

25. Serembus, J.F. and P.A. Riccio. Relationship Between Student Engagement and Outcomes for Online Master of Science in Nursing Students. Journal of Nursing Education. 2019; 58(4): 207-213; Available from: https://doi.org/10.3928/01484834-20190321-04.

26. Bolliger, D.U. and C. Halupa. Online student perceptions of engagement, transactional distance, and outcomes. Distance Education. 2018; 39(3): 299-316; Available from: https://doi.org/10.1080/01587919.2018.1476845.

27. Mimirinis, M., What the students do online in blended learning environments: deep, surface and strategic approach, in Proceedings of EdMedia 2016World Conference on Educational Media and Technology. 2016, Association for the Advancement of Computing in Education (AACE). 2016; Available from: https://www.learntechlib.org/primary/p/173115/.

28. Liang, J. How Can Physicians' Learning Styles Drive the Planning of the Continuing Medical Education. Fudan Education Forum. 2006(R-4): 87-90; Available from: http://en.cnki.com.cn/Article_en/CJFDTOTAL-GWZX200603020.htm. 
29. Newble, D.I. and M.I. Gordon. The learning style of medical students. Med Educ. 1985; 19(1): 3-8; Available from: https://doi.org/10.1111/j.13652923.1985.tb01132.x.

30. Kieser, J., P. Herbison, N. Waddell, T. Kardos, and P. Innes. Learning in oral biology: a comparison between deep and surface approaches. The New Zealand dental journal. 2006; 102(3): 64-68; Available from: https://pubmed.ncbi.nlm.nih.gov/16986303.

31. Fells, R.E. Teaching a subject like negotiation: How might we encourage deep learning? in A. Herrmann and M. M. Kulski (Eds), Expanding Horizons in Teaching and Learning. Proceedings of the 10th Annual Teaching Learning Forum: Curtin University of Technology. 2001; Available from: http://lsn.curtin.edu.au/tlf/tlf2001/fells.html.

32. Tiwari, A., S. Chan, E. Wong, D. Wong, C. Chui, A. Wong, et al. The effect of problem-based learning on students' approaches to learning in the context of clinical nursing education. Nurse Education Today. 2006; 26(5): 430-438; Available from: https://doi.org/10.1016/j.nedt.2005.12.001.

33. Tan, G.J.S., Promoting Deep Learning with PBL, in The 4th International Research Symposium on Problem-Based Learning (IRSPBL). 2013; Available from: http://tree.utm.my/wp-content/uploads/2013/11/Promoting-Deep-Learning-with-PBL.pdf

34. Liu, Y., Y. Zhao, and J. Xie. The Exploration and Practice of Relatives and Friends Health Management on Medical Students' Comprehensive Quality Training. Medicine \& Society. 2014; 27(8): 94-96; Available from:

http://qikan.chaoxing.com/detail_38502727e7500f26a93334682ed05d6afe45e94733f591291921b0a3ea255101fc1cf1fbb4666ae67037468ca016b4fb9

35. Abdous, M. and C.J. Yen. A predictive study of learner satisfaction and outcomes in face-to-face, satellite broadcast, and live video-streaming learning environments. Internet and Higher Education. 2010; 13(4): 248-257; Available from: https://doi.org/10.1016/j.iheduc.2010.04.005.

36. Chu, Y.T. and L.M. Walters. The question-asking behavior of Asian students in an American university classroom. Journal of English as an International Language. 2013; 8(2): 10; Available from: http://connection.ebscohost.com/c/articles/94899070/question-asking-behavior-asian-students-americanuniversity-classroom.

37. Kochar, A., J. Rymer, and Z. Samad. Disrupting Fellow Education Through Group Texting: WhatsApp in Fellow Education? Journal of the American College of Cardiology. 2018; 72(25): 3366-3369; Available from: https://doi.org/10.1016/j.jacc.2018.11.007.

38. Vela, K. Using Slack to communicate with medical students. Journal of the Medical Library Association. 2018; 106(4): 504-507; Available from: https://doi.org/10.5195/jmla.2018.482.

39. Minerick, A., Student Led Example Problems in a Graduate-Level Advanced Transport Phenomena Course, in 122nd ASEE Annual Conderence \& Exposition. 2015; Available from: https://peer.asee.org/24766.

40. O'Doherty, D., M. Dromey, J. Lougheed, A. Hannigan, J. Last, and D. McGrath. Barriers and solutions to online learning in medical education - an integrative review. BMC Med Educ. 2018; 18(1): 130; Available from: https://doi.org/10.1186/s12909-018-1240-0.

\section{Tables}

Table 1. General information of recovered questionnaires in two groups

\begin{tabular}{|lllll|}
\hline Questionnaire & People & $\begin{array}{l}\text { Number } \\
\text { Female }\end{array}$ & Male & $\begin{array}{l}\text { Age } \\
(M \pm S D)\end{array}$ \\
\hline OSE & Final-year students & 18 & 3 & $22.95 \pm 0.67$ \\
\hline \multirow{2}{*}{ R-SPQ-2F } & Non-final-year students & 36 & 6 & $21.26 \pm 1.31$ \\
\hline & Final-year students & 17 & 3 & $22.95 \pm 0.83$ \\
\hline TSES & Non-final-year students & 34 & 6 & $21.85 \pm 0.80$ \\
\hline
\end{tabular}

Table 2. Results of Online Student Engagement (OSE) Scale Questionnaire on final-year students 


\begin{tabular}{|c|c|c|}
\hline & $\begin{array}{l}\text { Characteristic and very characteristic of me } \\
\mathrm{n}(\%)\end{array}$ & $M \pm S D$ \\
\hline Skills & & $3.95 \pm 0.91$ \\
\hline 1.Study regularly & $15 \rrbracket 71.43 \rrbracket$ & $3.86 \pm 0.91$ \\
\hline 3.Staying up on reading & $15 \bigotimes 71.43 \bigotimes$ & $3.95 \pm 1.02$ \\
\hline 4.Looking over class notes & $11 \otimes 52.38 \bigotimes$ & $3.62 \pm 0.97$ \\
\hline 5.Being organized & $16 \otimes 76.19 \bigotimes$ & $4.10 \pm 0.89$ \\
\hline 6.Listening/reading carefully & $16 \bigotimes 76.19 \bigotimes$ & $4.10 \pm 0.89$ \\
\hline 7.Taking good notes & $16 \otimes 76.19 \bigotimes$ & $4.10 \pm 0.77$ \\
\hline Emotion & & $4.05 \pm 0.81$ \\
\hline 2.Putting forth effort & 17凶80.95囚 & $4.19 \pm 0.87$ \\
\hline 8.Finding ways to make materials relevant & $15 \bigotimes 71.43 \rrbracket$ & $4.00 \pm 0.77$ \\
\hline 9.Applying to my life & 17刃80.95囚 & $4.00 \pm 0.77$ \\
\hline 10.Finding ways to make materials interesting & $14 \llbracket 66.67 \rrbracket$ & $4.05 \pm 0.86$ \\
\hline 11.Really desire to learn & $16 \bigotimes 76.19 \bigotimes$ & $4.00 \pm 0.84$ \\
\hline Participation & & $3.41 \pm 0.99$ \\
\hline 12.Having fun in online chats or discussion & $14 \llbracket 66.67 \rrbracket$ & $3.86 \pm 0.85$ \\
\hline 13.Participating actively in forums & $10 \rrbracket 47.62 \rrbracket$ & $3.38 \pm 1.07$ \\
\hline 14. Help fellow students & $13 \llbracket 61.90 \rrbracket$ & $3.57 \pm 1.12$ \\
\hline 17.Engage in online conversations & $11 \llbracket 52.38 \rrbracket$ & $3.57 \pm 0.87$ \\
\hline 18.Posting regularly in forum & $6 \rrbracket 28.57 \rrbracket$ & $3.24 \pm 0.94$ \\
\hline 19.Get to know other students & $5 \llbracket 23.81 \rrbracket$ & $2.86 \pm 0.85$ \\
\hline Performance & & $3.45 \pm 1.09$ \\
\hline 15.Do well on tests & $10 \rrbracket 47.62 \rrbracket$ & $3.43 \pm 1.21$ \\
\hline 16.Get good grade & $9 \llbracket 42.86 \rrbracket$ & $3.48 \pm 0.98$ \\
\hline Overall & & $3.75 \pm 0.97$ \\
\hline
\end{tabular}

Table 3. Results of R-SPQ-2F questionnaire on final-year students 
$\mathrm{n}(\%)$

DA

$3.26 \pm 1.12$

DM

$3.24 \pm 1.20$

1.I find that at times studying gives me a feeling of deep personal satisfaction.

$3.70 \pm 1.13$

5. I feel that virtually any topic can be highly interesting once I get into it.

$12(60.0)$

$3.70 \pm 1.13$

9.I find that studying academic topics can at times be as exciting as a good novel or movie.

$14(70.0)$

$3.85 \pm 1.18$

13.I work hard at my studies because I find the material interesting.

$7(35.0)$

$3.10 \pm 1.17$

17.I come to most classes with questions in mind that I want answering.

$10(50.0)$

$3.35 \pm 0.99$

DS

$2(10.0)$

$2.20 \pm 0.83$

$3.28 \pm 1.05$

2. I find that I have to do enough work on a topic so that I can form my own conclusions before I am satisfied.

6. I find most new topics interesting and often spend extra time trying to obtain more information about them.

10. I test myself on important topics until I understand them completely.

$12(60.0)$

$3.60 \pm 1.05$

14. I spend a lot of my free time finding out more about interesting topics which have been discussed $4(20.0)$

$17(85.0)$

$3.40 \pm 1.05$ in different classes.
18. I make a point of looking at most of the suggested readings that go with the lectures.
$4(20.0)$
$2.70 \pm 0.92$

SA

$2.13 \pm 1.26$

SM

$2.03 \pm 1.20$

3. My aim is to pass the course while doing as little work as possible.

$2.25 \pm 1.21$

7. I do not find my course very interesting so I keep my work to the minimum.

$3(15.0)$

$2.40 \pm 1.19$

11. I find I can get by in most assessments by memorizing key sections rather than trying to

$5(25.0)$

$1.90 \pm 1.07$ understand them.

15. I find it is not helpful to study topics in depth. It confuses and wastes time, when all you need is a $3(15.0)$

$2(10.0)$ passing acquaintance with topics.

19. I see no point in learning material which is not likely to be in the examination.

$5(25.0)$

$1.60 \pm 1.14$

SS

$2.23 \pm 1.32$

4. I only study seriously what's given out in class or in the course outlines.

$6(30.0)$

$2.60 \pm 1.35$

8. I learn some things by rote, going over and over them until I know them by heart even if I do not understand them.

$8(40.0)$

$2.75 \pm 1.16$

12. I generally restrict my study to what is specifically set as I think it is unnecessary to do anything

$3(15.0)$

$1.65 \pm 1.14$ extra.

16. I believe that lecturers shouldn't expect students to spend significant amounts of time studying material everyone knows won't be examined.

$2(10.0)$

$1.55 \pm 1.05$

20. I find the best way to pass examinations is to try to remember answers to likely questions.

7 (35.0)

$2.60 \pm 1.43$

Overall

$2.70 \pm 1.32$

Table 4. Results of TSES questionnaire from tutors for the teaching of final-year dental students. 


\begin{tabular}{|c|c|c|}
\hline & $\begin{array}{l}\text { Number of Scores more than } \\
5 \\
n(\%)\end{array}$ & $M \pm S D$ \\
\hline Efficacy in Student Engagement & & $6.50 \pm 1.44^{\mathrm{a}}$ \\
\hline 1. How much can you do to get through to the most difficult students? & $15(65.22)$ & $6.13 \pm 1.71$ \\
\hline 2. How much can you do to help your students think critically? & $19(82.61)$ & $6.87 \pm 1.63$ \\
\hline 4. How much can you do to motivate students who show low interest in school work? & $17(73.91)$ & $6.13 \pm 1.22$ \\
\hline 6. How much can you do to get students to believe that they can do well in school work? & 19(82.61) & $6.83 \pm 1.34$ \\
\hline 9. How much can you do to help your student's value learning? & $20(86.96)$ & $6.87 \pm 1.42$ \\
\hline 12. How much can you do to foster student creativity? & $21(91.30)$ & $6.96 \pm 1.36$ \\
\hline 14. How much can you do to improve the understanding of a student who is failing? & $15(65.22)$ & $6.04 \pm 1.11$ \\
\hline 22. How much can you assist families in helping their children do well in school? & $15(65.22)$ & $6.17 \pm 1.47$ \\
\hline Efficacy in Instructional Strategies & & $6.76 \pm 1.42^{\mathrm{a}}$ \\
\hline 7. How well can you respond to difficult questions from your students? & $21(91.30)$ & $7.22 \pm 1.31$ \\
\hline 10. How much can you gauge student comprehension of what you have taught? & $21(91.30)$ & $6.87 \pm 1.36$ \\
\hline 11. To what extent can you craft good questions for your students? & $21(91.30)$ & $7.09 \pm 1.35$ \\
\hline 17. How much can you do to adjust your lessons to the proper level for individual students? & $13(56.52)$ & $6.48 \pm 1.53$ \\
\hline 18. How much can you use a variety of assessment strategies $\rrbracket$ & $16(69.57)$ & $6.43 \pm 1.34$ \\
\hline $\begin{array}{l}\text { 20. To what extent can you provide an alternative explanation or example when students are } \\
\text { confused? }\end{array}$ & $20(86.96)$ & $6.83 \pm 1.27$ \\
\hline 23. How well can you implement alternative strategies in your classroom? & $16(69.57)$ & $6.52 \pm 1.65$ \\
\hline 24. How well can you provide appropriate challenges for very capable students? & $16(69.57)$ & $6.65 \pm 1.50$ \\
\hline Efficacy in Classroom Management & & $6.68 \pm 1.44^{\mathrm{a}}$ \\
\hline 3. How much can you do to control disruptive behavior in the classroom? & $19(82.61)$ & $6.96 \pm 1.52$ \\
\hline 5. To what extent can you make your expectations clear about student behavior? & $18(78.26)$ & $6.61 \pm 1.27$ \\
\hline 8. How well can you establish routines to keep activities running smoothly? & $18(78.26)$ & $6.83 \pm 1.44$ \\
\hline 13. How much can you do to get children to follow classroom rules? & $21(91.30)$ & $6.91 \pm 1.31$ \\
\hline 15. How much can you do to calm a student who is disruptive or noisy? & $16(69.57)$ & $6.39 \pm 1.50$ \\
\hline 16. How well can you establish a classroom management system with each group of students? & $17(73.91)$ & $6.78 \pm 1.57$ \\
\hline 19. How well can you keep a few problem students from ruining an entire lesson? & $18(78.26)$ & $6.70 \pm 1.36$ \\
\hline 21. How well can you respond to defiant students? & $15(65.22)$ & $6.26 \pm 1.57$ \\
\hline Overall & & $6.65 \pm 1.43$ \\
\hline
\end{tabular}

a: ANOVA data analysis was made among three different categories, and no significance was found.

Table 5. Advantages of Combined mode of courses on dental virtual clerkship education compared to traditional by-chair clerkship education

\begin{tabular}{|lll|}
\hline Items & Traditional by-chair clerkship & Dental virtual clerkship \\
\hline $\begin{array}{l}\text { Understanding } \\
\text { of Knowledge }\end{array}$ & Revision in free time by themselves & $\begin{array}{l}\text { Key points of practice were summarized and revised, which make the } \\
\text { practice more relative to theory }\end{array}$ \\
\hline Interaction & $\begin{array}{l}\text { Not easy for students who are generally fearing } \\
\text { embarrassment and uncomfortable with asking questions in } \\
\text { public [36] }\end{array}$ & $\begin{array}{l}\text { "Real-time" connection via Wechat, which makes the asking-and- } \\
\text { answering or discussion easier [37, 38] }\end{array}$ \\
\hline Re-watch & Could not re-watch & $\begin{array}{l}\text { Recordings of the Wechat live broadcasting or PPT presentation } \\
\text { materials were available for re-watching at students' own pace } \\
\text { afterwards [39] }\end{array}$ \\
\hline
\end{tabular}

\section{Figures}




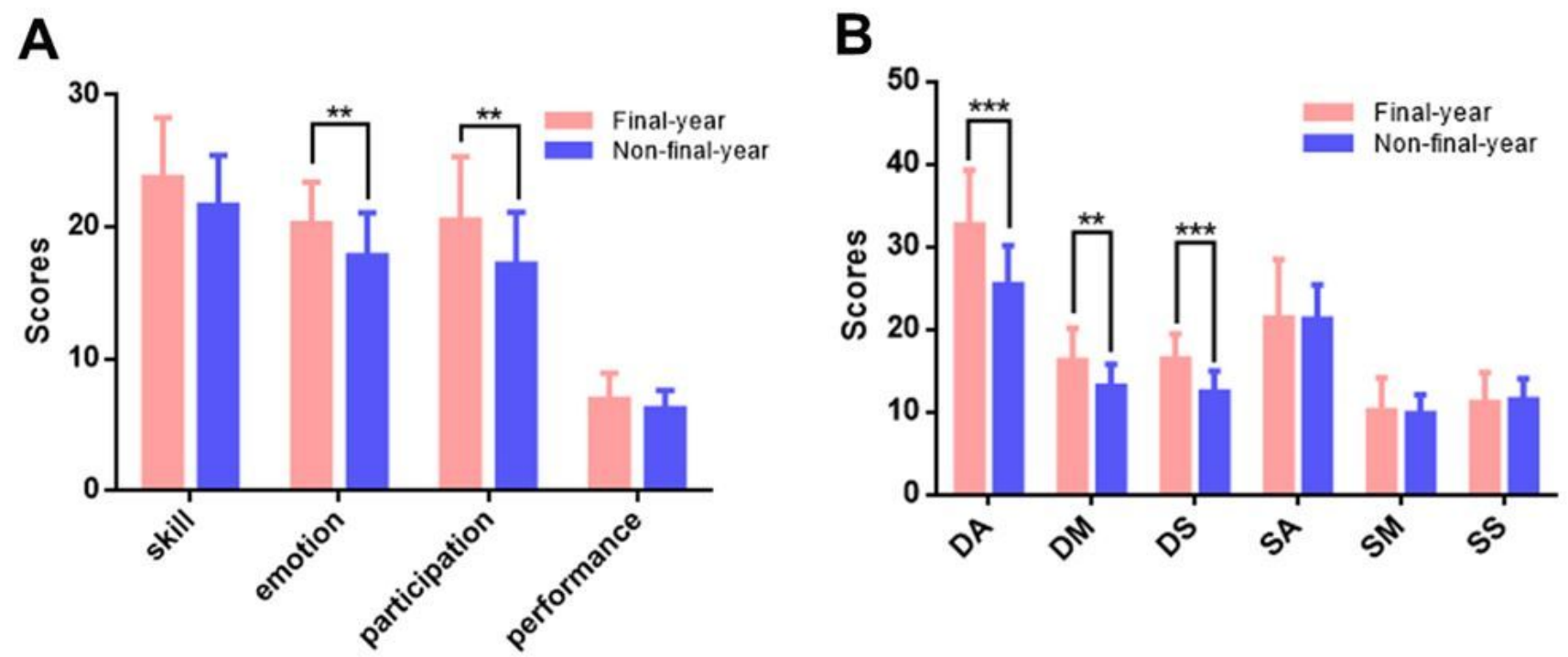

Figure 1

Comparison of OSE and SPQ scores between the final-year and non-final-year dental students. A. OSE scores comparison, the total score of emotion and participation categories were significantly higher in final-year group $(\mathrm{P}<0.01)$. B. Total scores of $\mathrm{R}-\mathrm{SPQ}-2 \mathrm{~F}$ including deep motive and strategy were significantly higher in final-year group (DA,DS: $P<0.001, D M: P<0.01)$. SA: superficial approach, SM: superficial motive, SS: superficial strategy, DA: deep approach, DM: deep motive, DS: deep strategy. SA=SM+SS, DA=DM+DS. 